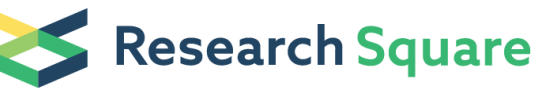

\section{Metaheuristics in the Decentralization of Emergency Care.}

\section{Eric Lucas dos Santos Cabral}

UFRN: Universidade Federal do Rio Grande do Norte

Wilkson Ricardo Silva Castro

UFRN: Universidade Federal do Rio Grande do Norte

Davidson Rogério de Medeiros Florentino

UFRN: Universidade Federal do Rio Grande do Norte

João Florêncio da Costa Junior

UFRN: Universidade Federal do Rio Grande do Norte

Talita Dias Chagas Frazão

UFRN: Universidade Federal do Rio Grande do Norte

Claudia Aparecida Cavalheiro Francisco

UFRN: Universidade Federal do Rio Grande do Norte

Ricardo Pires de Souza

UFRN: Universidade Federal do Rio Grande do Norte

Amália Cinthia Meneses Rêgo

Universidade Potiguar Unidade Salgado Filho

IRAMI ARAÚJO-FILHO ( $\nabla$ irami.filho@uol.com.br)

Universidade Federal do Rio Grande do Norte https://orcid.org/0000-0003-2471-7447

Marco Antônio Leandro Cabral

UFRN: Universidade Federal do Rio Grande do Norte

\section{Research}

Keywords: Medical Emergency Service, Ambulances, Optimization, Simulation, Response Time

Posted Date: December 14th, 2020

DOI: https://doi.org/10.21203/rs.3.rs-121691/v1

License: (1) This work is licensed under a Creative Commons Attribution 4.0 International License.

Read Full License 


\section{Metaheuristics in the decentralization of emergency}

care.

Eric Lucas dos Santos Cabral ${ }^{1}$, Wilkson Ricardo Silva Castro², Davidson Rogério de Medeiros Florentino3; João Florêncio da Costa Junior ${ }^{4}$, Talita Dias Chagas Frazão5, Claudia Aparecida Cavalheiro Francisco ${ }^{6}$, Ricardo Pires de Souza ${ }^{7}$, Amália Cinthia Meneses Rêgo ${ }^{8}$, Irami Araújo Filho*9 $^{*}$ Marco Antônio Leandro Cabral ${ }^{10}$

${ }^{1}$ Master in Production Engineering by the Graduate Program in Production Engineering at UFRN / Natal-RN, Brazil. Federal University of Rio Grande do Norte, Zip code: 59078-970; Technology Center, Department of Production Engineering, Natal / RN - Brazil. E-mail: ericlucascabral94@gmail.com;

${ }^{2}$ Master's degree in Production Engineering by the Graduate Program in Production Engineering at UFRN / Natal-RN, Brazil. Federal University of Rio Grande do Norte, Zip code: 59078-970; Technology Center, Department of Production Engineering, Natal / RN - Brazil. E-mail: wilkson.rsc@gmail.com;

${ }^{3}$ Master in Production Engineering by the Graduate Program in Production Engineering at UFRN / Natal-RN, Brazil. Federal University of Rio Grande do Norte, Zip code: 59078-970; Technology Center, Department of Production Engineering, Natal / RN - Brazil. E-mail: davidsonflorentino@gmail.com;

\footnotetext{
${ }^{4}$ Master's degree in Production Engineering by the Graduate Program in Production Engineering at UFRN / Natal-RN, Brazil. School of Applied Social Sciences, Education, Arts and Humanities, Laureate International Universities (Potiguar University), Zip code: 59082-902, Natal, Brazil. Email: ifci1977@googlemail.com;
} 
${ }^{5}$ Master's degree in Production Engineering by the Graduate Program in Production Engineering at UFRN / Natal-RN, Brazil. Federal University of Rio Grande do Norte, Zip code: 59078-970; Technology Center, Department of Production Engineering, Natal / RN - Brazil. E-mail: thalytachaggas@gmail.com;

${ }^{6}$ Ph.D. Science and Petroleum Engineering by the Graduate Program in Science and Petroleum Engineering at UFRN/Natal-RN, Brazil. Federal University of Rio Grande do Norte, Zip code: 59078-970; Technology Center, Department of Production Engineering, Natal / RN - Brazil. Email: claudiacavalheirof@gmail.com.

7 Ph.D. Mechanical Engineering by the Graduate Program in Mechanical Engineering at UFRN/Natal-RN, Brazil. Federal University of Rio Grande do Norte, Zip code: 59078-970; Technology Center, Department of Production Engineering, Natal / RN - Brazil. E-mail: ripiso@gmail.com.

${ }^{8}$ Ph.D. in Health Science by the Graduate Program in Health Sciences at UFRN/Natal-RN, Brazil. Postgraduate Program in Biotechnology at Potiguar University/ UnP - Laureate International Universities, Zip code: 59082-902, Natal, Brazil.E-mail: regoamalia@gmail.com.

${ }^{9}$ Ph.D. in Health Science by the Graduate Program in Health Sciences at UFRN/Natal-RN, Brazil. Postgraduate Program in Biotechnology at Potiguar University/ UnP - Laureate International Universities, Zip code: 59082-902, Natal/RN - Brazil. Federal University of Rio Grande do Norte, Zip code: 59078-970; Health Sciences Center, Department of Surgery, Natal / RN - Brazil. Email: irami.filho@uol.com.br.

${ }^{10} \mathrm{Ph} . \mathrm{D}$. Mechanical Engineering by the Graduate Program in Mechanical Engineering at UFRN/Natal-RN, Brazil. Federal University of Rio Grande do Norte, Zip code: 59078-970; Technology Center, Department of Production Engineering, Natal / RN - Brazil. E-mail: mcabral2014@gmail.com. 
*Correspondence: Irami Araújo-Filho - MD - Ph.D.

Ph.D. in Health Science by the Graduate Program in Health Sciences at UFRN/Natal-RN, Brazil. Postgraduate Program in Biotechnology at Potiguar University/ UnP - Laureate International Universities, Zip code: 59082-902, Natal/RN - Brazil. Federal University of Rio Grande do Norte, Zip code: 59078-970; Health Sciences Center, Department of Surgery, Natal / RN - Brazil. Email: irami.filho@uol.com.br.

\section{Abstract}

Background: The growth of the urban population exerts considerable pressure on municipalities' public managers to focus their attention on providing emergency medical care that meets the growing demand for emergency pre-hospital medical care. Currently, there are a significant number of traffic accidents and other serious occurrences, such as heart attacks, drownings, epidemics, fires and disasters (floods, landslides, earthquakes) that demand a prompt and seamless response from pre-hospital medical care. As a result of such scenario, the present article endeavours to apply a dual-coverage mathematical model (DSM-Double Standard Model) to define the optimal location of the Emergency Medical Service (SAMU) decentralized dispatch bases in Natal / RN and conduct a simulation study to evaluate the displacement of ambulances between such bases.

Patients and methods: The methodological course that was followed by this research constitute for 12 steps, so as to the location of decentralized bases for sending emergency ambulances was established using the DSM model and the simulation model was performed using the FlexSim software $^{\odot}$ version 2018 evaluating base coverage in relation to the total number of calls by demand points for different scenarios.

Results: The results obtained throughout the research demonstrated the feasibility of redefining the decentralized bases of SAMU / Natal ambulances as a strategy to reduce response time and guarantee compliance with performance parameters established by international organizations 
(the World Health Organization, for instance, establishes the time of 8 minutes for emergency medical service calls response). The simulation study showed a significant reduction in response time, by up to $60 \%$ in some cases.

Conclusion: The proposition of new locations for the decentralized dispatch bases of the SAMU/Natal can provide an overall significant reduction on the ambulance response time, so as to contributes to expedite the initiation of treatment of patients, if necessary, sent to hospitals.

Keywords: Medical Emergency Service, Ambulances, Optimization, Simulation, Response Time.

\section{Background}

The growth of the urban population exerts pressure on municipalities' public managers to focus their attention on providing emergency medical care that meets the needs of emergency pre-hospital medical care. It is estimated that, by 2050 , urban areas should have a population of 6.29 billion people, equivalent to $69 \%$ of the world's total population.[1] Heavily concentrated urban areas are more prone to a significant number of traffic accidents and other serious occurrences, such as heart attacks, drownings, epidemics, fires and disasters (floods, landslides, earthquakes) that demand a prompt and seamless response from pre-hospital medical care.

Studies in Latin America (mainly in Brazil) demonstrate that most of the deaths that occur in the region are caused by urban violence and traffic accidents.[2] Only in Brazil in the years of 2014 and 2016, according to statistics released by the,3,4 there were 43,075 traffic-related deaths and 62,517 homicides.

Aging societies are increasing the demands for nursing homes and health care facilities in the face of a shortage of staff, creating a critical need for optimal efficiency.[5] Delayed prehospital response time (PRT) is the crucial cause for delayed treatment, generally resulting in a bleak outcome for patients with multiple severe traumas, as well as for those with cerebrovascular diseases including stroke, myocardial infarction and, finally, presumed cardiac arrest, which have a very narrow window of time for effective treatment. PRT delay is a well-known fact that affects the survival of patients with out-of-hospital cardiac arrest.[6]

Response time is the key indicator of this service, which is defined as the time between the notification of an occurrence and the arrival of the ambulance at the scene. This is the main 
emergency medical service performance measure. According to the World Health Organization, an ideal response time is less than 8 minutes.[7]

In order to reduce ambulance response time, besides the determination of optimum locations for ambulance dispatch bases, it is just as important to choose which ambulance should attend each call. The policy of only sending the ambulance closer to the location may compromise the ability to serve future demands.[8] According to the specialized literature there are several ways to reduce ambulance response time; establishing dynamic repositioning and dispatching ambulances that are in motion are two of the most common.[9]

Most allocation models adopted to address the problem of ambulance circulation do not perform adequately when ambulances are busy on other calls. As a result of this, many authors favour the double coverage model.[10]

The present article endeavours to analyse the possibility of applying a dual-coverage mathematical model in order to determine the optimum location for decentralized bases for the Natal Emergency Medical Service (SAMU) through a simulation study for the evaluation of queueing indicators of calls for urgency and red code emergency, enabling the model to offer efficient support to the relevant decision making process on dispatching facilities as to decrease response time and approach internationally recognized operating parameters.

\section{Methods}

Scopus / Embase, NCBI (PubMed) and Science Direct databases were searched on May 5th, 2017 for English language articles from 2007 to 2018. The following search terms were used: "Emergency Medical Services" and "Response Time". Titles and abstracts were independently reviewed by four reviewers. Previous work at this time was entered using variations of the keywords mentioned, such as "Reaction Time", "Emergency Services" and "Optimization".

Lilacs database was not consulted as it is indexed to sciELO, which in turn is indexed to PubMed. Google Scholar was not considered due to reviewers' preference for using peerreviewed databases. Figure 1 explains the methodological course that was followed by this research, arranging in a schematic representation the steps taken by the authors as well as the resources necessary for its replication to be systematized (Figure 1). 
Figure 1 is composed by the following steps:

1. Conduct database research in order to find qualified works that can offer a robust theoretical framework for the present study.

2. Establish partnerships between the Health Secretary, the SAMU board of directors and the research team.

3. Access the database (SSO and SYSTRACKS) for ambulance response time information, boroughs' demand, call times, ambulance GPS data, and operational retention information for stretchers and other equipment.

4. Generate data analysis and reports detailing response time information and operational difficulties related to ambulance displacement (effect of stretchers retention, for example) using Excel 2016. The equipment utilized had the following configurations: Windows 10 Pro 64-bit, Intel (R) Core (TM) i5-7500 CPU @ 3.40GHz (4 CPUs), 3.4GHz.

5. Present SAMU / Natal operational data analyses result in scientific conferences and qualified journals.

6. Evaluate the input data of the DSM (Double Standard Model) algorithm to determine the arrangement of the decentralized bases of emergency service ambulances.

7. Program the DSM model in AIMMS ( 2018 version proposed by[11] - a study developed in the city of Tijuana, Mexico. The choice of the proposed model was based on the confirmation that the operational challenges of the local medical emergency service (SAMU Natal) were quite similar to those experienced by the Tijuana medical emergency medical service (Mainly population number, territorial area and availability of ambulances to perform the service). The machine used to evaluate DSM results had the following settings: Windows 10 Home 64-bit, Intel (R) Core (TM) i5 CPU M 450 @ 2.40GHz (4 CPUs), 2.4GHz

8. Determine dispatch base positions according to what has been established by the DSM model.

9. Present simulation study proposal to evaluate the coverage of the bases in relation to the total number of calls by demand points.

10. Run the simulation model through FlexSim@ 2018 version with licence to utilize the extension ExpertFit@ to generate probability distributions. 
11. Simulate scenario through FlexSim@ 2018 version.

12. Share results with the relevant stakeholders in the project.

Authors such as,[12-16] argue that it is necessary working with a location model of facilities aligned to a simulation study. Figure 1 ilustrate the stages for the simulation study. The steps for the simulation study are proposed by Law[17] and consist of the following decisions:

1. Define problem and do research planning.

2. Collect data and determined model.

3. Was the documentation validity determined?

4. Develop a computer program to verify the data.

5. Test the pilot model.

6. Is the programmed model valid?

7. Design the experiment.

8. Run the developed model.

9. Analyse output data.

10. Present documents and results.

\section{Results}

The city of Natal has a population of around 877,740 inhabitants.[18] The Natal Emergency Mobile Service (SAMU) has 9 basic ambulances and 3 advanced ambulances to serve the population (used in exceptional cases when there is an unusual increase in demand), which represents the proportion of a basic support ambulance for every 98,000 inhabitants; this scenario radically differs from the reality of North American cities, for instance, wherein there is a proportion of one ambulance per 51,000 inhabitants, according to.[19]

The scenario is aggravated by several factors such as the lack of resources to carry out the routine activities of the Emergency Medical Service, the growing urban violence, the maladministration of public hospitals.[20] The average response time quantified by the SSO system - the Online Health System consulted daily by the medical regulation team, which is the main indicator to evaluate the SAMU Natal service efficiency - was 44 minutes in 2018. Such 
performance indicators, given the approximate area of the city of Natal $\left(160 \mathrm{~km}^{2}\right)$, reveal a clear need to restructure the services in order to satisfactorily meet current and future demand.

Tracing a parallel with other world authorities in medical emergencies; the National Fire Protection Association in the United States recommends that the basic services to support life arrive at the emergency local within 4 minutes, whereas the advanced life support providers must arrive within 8 minutes for every call demanding emergency medical care.[21]

This American standard will be adopted on the Mathematic Model DSM utilized in the current article as to define the dispatch positions for the decentralised SAMU bases in Natal.

Determining the optimum location for available resources, specifically ambulances is one the major problems faced by a Medical Emergency Service.[22]

Li et al [23] has presented a recent systematized discussion on coverage models used to define ambulance dispatch positions, explaining solution strategies as well as outlining that mathematical programming techniques such as Integer Linear Programming (ILP) and metaheuristic approaches such as genetic algorithms were already used by researchers on the subject.

Double Standard Model (DSM) was one of the most successful approaches. The model was used to optimize the dispatch location for ambulance services in Canada, Austria, Mexico and the United States, demonstrating that such model is accepted and regularly used for the ambulance localization problem. [11,22,24,25]

The Hypercube model is also an important model used to determine optimum ambulance dispatch locations; as it validates the optimization solution in a way that if the solution is viable, the algorithm is finalised; otherwise, it generates new values. Thus, it is possible to state that both approaches are equivalent in terms of solution quality, but the Hypercube model is particularly efficient for it requires less computational time. [26-31]

The recent work published by [11] applies DSM throughout successive time periods to calculate the fluctuating displacement times throughout the day. Hence, we presently sustain that such studies support a plausible extension for DSM, considering multiple scenarios executed simultaneously to obtain robust solutions, and corresponding to the strategy that is better adjusted to the local reality of SAMU Natal operations. 
$\operatorname{Max} \sum_{s \in S} \rho^{s} \sum_{i \in V} w_{i}^{S} d_{i}^{s} z_{i}$

$\sum_{j \in V_{i}^{r_{2}}} x_{j} \geq 1(i \in V)$

$\sum_{i \in V} d_{i}^{s} y_{i} \geq \alpha \sum_{i \in V} d_{i}^{s}(s \in S)$

$\sum_{i \in W_{i}^{r_{1}}} x_{j} \geq y_{i}+z_{i}(i \in V)$

$z_{i} \leq y_{i}(i \in V)$

$\sum_{j \in W} x_{j}=p$

$x_{i} \leq p_{i}(j \in W)$

$y_{i}, z_{i} \in\{0,1\}(i \in V)$

$x_{j}$ integer $(j \in W)$

Where:

$i$ : Index representing the points of demand;

$j:$ Index that represents the possible installations;

$r^{1} \mathrm{e} r^{2}$ : rays of distances or pre-established times for the execution of the service;

$V$ : Set of demand points $\left(V=\left\{v_{1}, \ldots \ldots, v_{n}\right\}\right)$;

$W$ : Set of points of possible installations $\left(W=\left\{v_{n+1}, \ldots \ldots, v_{n+m}\right\}\right)$;

$E$ : Set of "edges" in the network $\left(E=\left\{\left(v_{i}, v_{j}\right) \mid v_{i} \in \quad V \quad e \quad v_{j} \in W\right\}\right)$;

$G=(V \cap W, E)$

$y_{i}$ : Demands on vertex $v_{i} \in V$;

$x_{j}$ : Variable indicating the number of ambulances located in $v_{n+j} \in W$;

$z_{i}$ : Binary decision variable; is equal to 1 if $v_{i}$ is covered at least time within radius $r$;

$\rho^{s}$ : Maximum number of ambulances to be located in the possible facilities $v_{n+j} \in W$;

$\rho:$ Total ambulances;

$\alpha$ : Proportion of demand to be covered in $\mathrm{r}$;

$d_{i, n+j}$ : Distance or time between point of demand and possible location;

$a_{i j}=\left\{\begin{array}{c}1, d_{i, n+j} \leq r \\ 0, \text { if not }\end{array} \forall v_{i} \in V, \forall \quad v_{n+j} \in W ;\right.$ 
$b_{i j}=\left\{\begin{array}{c}1, d_{i, n+j} \leq r^{2} \\ 0, \text { if not }\end{array} \forall v_{i} \in V, \forall \quad v_{n+j} \in W\right.$

$n$ : Number of demand points;

$m$ : Number of points of possible installations.

The results obtained from the implementation of the algorithm above supporting the understanding that the system of emergency mobile service of Natal has the capacity to attend the events that require emergency and emergency pre-hospital medical care within 14 minutes at most, in a scenario of double coverage in which the calls must be attended within 10 minutes in average.

Some scenarios in which there is feasibility and infeasibility of the DSM algorithm for the specific scenario studied are represented on table 1 and were proposed by the medical regulation team.

The results obtained from the implementation of the algorithm above supporting the understanding that the system of emergency mobile service of Natal has the capacity to attend the events that require emergency and emergency pre-hospital medical care within 14 minutes at most, in a scenario of double coverage in which the calls must be attended within 10 minutes in average.

Some scenarios in which there is feasibility and infeasibility of the DSM algorithm for the specific scenario studied are represented on table 1 and were proposed by the medical regulation team.

Table 1 demonstrates feasibility and unfeasibility of scenarios associated to the DSM algorithm parameters oscillation in the city of Natal. The minimum attendance values oscillated between 0.68 and 0,95 . This is the percentage of the total number of calls that must be answered by the emergency services, which ensures, in other words, that the metaheuristic presented achieves a feasible result from the model's relaxation. Such oscillation is in conformity with the value presented by [11] and raises the discussion about the possibility of the theoretical problem resolution adjusted to the reality of SAMU Natal.

Therefore, there will be a change in the occupancy rate of SAMU Natal ambulances which may lead to operational costs reduction through resources reallocations (human and materials) necessary to carry out the pre-hospital intervention procedures. Effectively reducing the 
ambulances displacement time in relation to the calling places will also help patients to be treated more quickly and if necessary, sent to hospitals.

Dibene et al [11] utilizes MATLAB@ alongside the CPLEX solution package. On the other hand, in the present study, it was opted to utilize the AIMMS@ software, a computational tool that presented a satisfactory performance to the expected results so far.

As to implement a more refined model to manage the current demand, the calls to SAMU Natal are classified based on time and date. Days were classified as working days (Monday to Friday) and recess (weekends and bank holidays). Time was divided in 6 hours segments: Morning from 06:00 a.m. to 12:00 p.m.; afternoon from 12:00 p.m. to 6:00 p.m.; Evening from 6:00 p.m. to 12:00 a.m.; and dawn from 12:00 a.m. to 6:00 a.m. The number of calls and the priority levels in each of these scenarios are displayed on Table 2.

It is possible to see on Table 2 that the call distribution during dawn, mornings, afternoons and evenings as well as the call priorities do not change significantly during working days or recesses; also, most calls happened during afternoons in both scenarios.

\section{Discussions}

Following the proposal for the determination of decentralized dispatch bases; it is reasonable to evaluate the representativeness with which the response time is presented in the conventional days, bank holidays and in the different shifts. From these comparatives, it will be possible to evaluate the gain or loss of performance in the object of study, allowing the drawing of inferences with the information generated.

Dibene et al [11] develops a table detailing response times based on reasonable expected times to the adequate performance of emergency medical series. Following the same method, the information between 2014 to 2017 were catalogued, thus allowing to draw some basic considerations: The majority of calls occurs during mornings and afternoons and take between 42 and 45 minutes to be attended during working days.

During the recess period, most calls take place between afternoon and evenings, taking around 39 to 41 minutes to be attended. The scenario considered adequate to position the decentralised dispatch bases validated by the Emergency Mobile Care Service directors can be 
found on Table 3.

The new proposal envisages the distribution of SAMU's decentralized base facilities in the four major areas in the city of Natal; also, it considers necessary to increase the number of decentralized bases so that there is an expansion in the coverage of the city's demand for calls; finally it deems unnecessary the purchasing of new basic support ambulances.

Compared to the current situation, the proposed model suggests the relocation of all decentralised bases. The results related to the possibility of nine ambulances and nine decentralised dispatch bases are prone to new evaluations as long as there are some circumstantial changes such as new requirements from the responsible public bodies.

In the present study, the data on 365 days of calls for prehospital medical care did not present values consistent with known probability distributions; therefore, the data was measured according to the abovementioned statistical tests.

As the FlexSim ${ }^{\circledR}$ software offers the possibility to consider empirical distributions to generate the simulation, empirical distributions were used to construct scenarios corresponding to before and after the facilities of the SAMU Natal decentralized dispatch bases.

Before the simulation, it is necessary to compare the generation of entities by a system variable and its corresponding in the real system. The purpose of this comparison is to understand if there are similarities between the real situation and the simulated situation. Figure 2 demonstrates the equivalency.

The blue bars represent actual calls by neighborhoods. The orange line represents simulated calls by neighborhoods. As to complement the graphical evaluation, analytical evaluations of the model's stability and quantity of replications are necessary in order to reach reliable conclusions in the present study; the equations and their respective variables with the mathematical procedures adopted in this study are expressed below. Equation (8) and (9) represent, respectively, the number of replications required for the model and the standard error, which informs the accuracy of the system variable chosen for evaluation $[17,32]$

$$
\begin{aligned}
& n^{*}=\left[n\left(h / h^{*}\right)^{2}\right] \\
& E=t_{1-\alpha / 2, n-1} * s / \sqrt{n}
\end{aligned}
$$


Where:

$n$ : Size;

$h:$ Precision;

$h^{*}$ : Aimed precision;

$n^{*}:$ Number of required replications;

$E$ : Standard error;

$t$ : Distribution $\mathrm{t}$ for $1-\alpha / 2$ with $\mathrm{n}-1$ degrees of freedom;

$s$ : Standard deviation of replication means;

$n$ : Number of observations in the sample.

In the present study, the number of replications equivalent to 5 simulations was used as initial value without recourse to the equation (8). The output results initially presented by FlexSim( software were evaluated. The system variable selected for analysis was average ambulance displacement time from the Average Stay Time dashboard (Table 4). The explanation of the calculation using equation (9) is presented in the text.

$$
\begin{aligned}
& E=2.776 * 2.47 / \sqrt{5} \\
& E=3.07 \mathrm{~s}
\end{aligned}
$$

The result (11) indicates that the data of the proposed model are stable and that the initial number of replications was sufficient to guarantee stability of the system, as the Standard Error presented a result equivalent to $3.07 \mathrm{~s}$.

From Table 5 it is possible to affirm that the proposition of new locations for the decentralized dispatch bases of the mobile emergency service in the city of Natal can provide an overall significant reduction on the ambulance response time. Nonetheless, it is also significant the number of locations that presented increased response time with the proposed scenario.

It is also possible to perceive on Table 5 that in the current model, a portion of boroughs in the city of Natal are no longer served due to the operational unfeasibility of the prehospital medical care system with the current base position presented by SAMU Natal. Figure 3 shows the results of Table 5 in graph form: 
The simulated time is represented by the orange bar. The real time is represented by the blue bar. The line in red represents the reduction evidenced from the positioning of the bases in the simulation model. Figure 3 shows that 17 boroughs out of 35 in total in the city of Natal presented a significant reduction in response time. 10 boroughs showed an increase of the response time. A total of 8 boroughs are not served with the current positioning of the bases, which indicates the failure of the current emergency system to cover all the calls demanded by the population.

\section{Conclusions}

The present study evaluated, through a case study methodology, the strategy of applying the coverage model (Double Standard Model) in the determination of the decentralized dispatch bases of the Mobile Emergency Service in the city of Natal.

As previously explained in the present article, the need for urgent medical care grows exponentially due to the increasingly dense urban area and the ever-growing levels of violent crimes, which places this service as a key public administration concern; fast urgent medical care response become thus a key performance indicator to measure the effectiveness of the public health system.

The following points are amongst the most important actions to be taken in order to increase the efficiency of the medical care response leading to a satisfactory pre-hospital care service: (1) adopting a strategy of positioning bases according to worldwide technical criteria; (2) offering reliable statistical analysis to the team that manages the local emergency medical services; (3) drawing up, from a multidisciplinary team, action plans to solve the potential deviations from the operational plan; (4) integrating municipal, state and federal instances with regards to public health management.

In view of what has been discussed, given the importance of the theme, it is believed necessary to stimulate the development of further studies as to understand the factors that affect response time results, which will allow a scientifically validated understanding of what can be done to reduce it. The cohort and control case studies that deal with the present subject and were considered in this article express descriptive statistics and robust decision models widely used; 
however, they merely expose the operational situations inherent to the management of the emergency service without questioning the extrinsic operating conditions that generate the performance reflected in the response time. The study developed by[33] clarifies these limitations in a review of recently published literature.

The present work has limitations related to the approximations necessary to the functionality of the implemented algorithm; namely: approximations as definitions of the demand point and ambulance trajectory through Euclidean distance. The major studies identified on the topic used GPS information to determine the actual displacement that was performed by the ambulances.

Another limitation faced by the authors was the non-free license of the FlexSimœ software, which offered initial difficulties to start the study. The use of unknown (empirical) probability distributions in the simulation study may hinder the replication of the work. Other models could be used as a comparative study and would achieve less computational effort to give the results expressed by this article: this is the case of the Hypercube Model.

Studies that deal with the use of mathematical models for ambulance dispatch bases converge to the understanding that increasing the availability of dispatch bases leads to a reduction of the response time demanded for the occurrences of pre-hospital medical care.

\section{Acknownledgements}

This study was financed in part by the Coordenação de Aperfeiçoamento de Pessoal de Nível Superior - Brasil (CAPES) -Finance Code 001. The Federal University of Rio Grande do Norte for the infrastructural and financial support necessary for this research.

\section{Authors' contributions}

ELSC and WRSC data analysis and critical review. DRMF and CACF acted as technical support the conclusions of the work. JFCJ and MALC contributed to the translation and critical review of the study. RPS and TDCF managed the project and was responsible for modeling the study. ACMR and IAF acted medical validation of the study modeling. 


\section{Funding}

Not applicable.

\section{Availability of data and materials}

The datasets used and analyzed during the current study are available from the corresponding author on reasonable request

\section{Ethics approval and consent to participate}

Not applicable.

\section{Consent for publication}

Not applicable.

\section{Competing interests}

The authors declare that they have no competing interests

\section{Author details}

${ }^{1}$ Master in Industrial Engineering (Operational Research and Logistics) by the Graduate Program in Industrial Engineering at UFRN (2018). Industrial Engineer from the Federal University of Rio Grande do Norte (2016). Has experience in the application of computational models in the health area (Location of Facilities, Multicriteria Decision Analysis, Queuing Theory and Simulation)

\section{References}

1. Zhao P, Chapman R, Randal E, Howden-Chapman P. Understanding Resilient Urban Futures: A Systemic Modelling Approach. Sustainability. 2013; 5(7):3202-3223.

2. Reichenheim ME, De Souza ER, Moraes CL, De Mello Jorge MHP, Da Silva CMFP, Minayo MCS. Violence and injuries in Brazil: the effect, progress made, and challenges ahead. Lancet. 201; 377(9781):1962-1975. 
3. Cerqueira D, Lima RS, Bueno S, et al. Atlas da Violência/Atlas of Violence; 2018. Available from: http://www.ipea.gov.br/portal/images/stories/PDFs/relatorio institucional/180604 atlas da violencia 2018.pdf. Access December 10, 2018.

4. Waiselfsz JJ. Mapa da violência/ Map of violence; 2016. Available from: http://www.mapadaviolencia.org.br/pdf2016/Mapa2016 armas web.pdf. Access December 10, 2018.

5. Chiou SY, Liao ZY. A real-time, automated and privacy-preserving mobile emergencymedical-service network for informing the closest rescuer to rapidly support mobileemergency-call victims. IEEE Access. 2018; 6:35787-35800.

6. Kim J, Kim CH, Shin S Do, Park JO. Prehospital Response Time Delays for Emergency Patients in Events of Concurrent Mass Casualty Incidents. Disaster Med Public Health Prep. 2018; 12(1):94-100.

7. Nogueira LC, Pinto LR, Silva PMS. Reducing Emergency Medical Service response time via the reallocation of ambulance bases. Health Care Manag Sci. 2016; 19(1):3142.

8. Bélanger V, Lanzarone E, Ruiz A, Soriano P. The Ambulance Relocation and Dispatching Problem. CIRRELT. 2015 Nov: 1-17.

9. Alanis R, Ingolfsson A, Kolfal B. A markov chain model for an EMS system with repositioning. Prod Oper Manag. 2013; 22(1):216-231.

10. Shariat-Mohaymany A, Babaei M, Moadi S, Amiripour SM. Linear upper-bound unavailability set covering models for locating ambulances: Application to Tehran rural roads. Eur J Oper Res. 2012; 221(1):263-272.

11. Dibene JC, Maldonado Y, Vera C, Oliveira M De, Trujillo L, Schütze O. Optimizing the location of ambulances in Tijuana, Mexico. Comput Biol Med. 2017;80(1):107-115.

12. Diggs LA, Sheth-Chandra M, De Leo G. Epidemiology of Pediatric Prehospital Basic Life Support Care in the United States. Prehosp Emerg Care. 2015;20(2):230-238.

13. Lam SSW, Nguyen FNHL, Ng YY, et al. Factors affecting the ambulance response times of trauma incidents in Singapore. Accid Anal Prev. 2015; 82:27-35. 
14. Soysal M. Closed-loop Inventory Routing Problem for returnable transport items. Transp Res Part D Transp Environ. 2016; 48:31-45.

15. Tlili T, Abidi S, Krichen S. A mathematical model for efficient emergency transportation in a disaster situation. Am J Emerg Med. 2018; 36(9):1585-1590.

16. Yousefli Z, Nasiri F, Moselhi O. Healthcare facilities maintenance management: a literature review. J Facil Manag. 2017;15(4):352-375.

17. Law A. Simulation modeling and analysis. 4th ed. New York: McGraw Hill; 2007.

18. Instituto Brasileiro de Geografia e Estatística/ Brazilian Institute of Geography and Statistics [homepage on the internet]. Estatística das cidades/City statistics; 2019. Available at: https://cidades.ibge.gov.br/. Access January 30, 2019.

19. Braun O, McCallion R, Fazackerley J. Characteristics of midsized urban EMS systems. Ann Emerg Med. 1990;19(5):536-546.

20. Camilo DGG, de Souza RP, Frazão TDC, Costa Junior JF. Multi-criteria analysis in the health area: selection of the most appropriate triage system for the emergency care units in natal. BMC Med Inform Decis Mak. 2020; 20(38):1-16.

21. Pons PT, Markovchick VJ. Eight minutes or less: Does the ambulance response time guideline impact trauma patient outcome? J Emerg Med. 2002; 23(1):43-48.

22. Gendreau M, Laporte G, Semet F. Solving an ambulance location model by tabu search. Locat Sci. 1997; 5(2):75-88.

23. Li X, Zhao Z, Zhu X, Wyatt T. Covering models and optimization techniques for emergency response facility location and planning: A review. Math Methods Oper Res. $2011 ; 74(3): 281-310$.

24. Liu Y, Li Z, Liu J, Patel H. A double standard model for allocating limited emergency medical service vehicle resources ensuring service reliability. Transp Res Part C Emerg Technol. 2016; 69:120-133.

25. Schmid V, Doerner KF. Ambulance location and relocation problems with timedependent travel times. Eur J Oper Res. 2010; 207(3):1293-1303.

26. Larson RC. A hypercube queuing model for facility location and redistricting in urban emergency services. Comput Oper Res. 1974; 1(1):67-95. 
27. Baptista S, Oliveira RC. A case study on the application of an approximated hypercube model to emergency medical systems management. Cent Eur J Oper Res. 2012; 20(4):259-281 .

28. De Souza RM, Morabito R, Chiyoshi FY, lannoni AP. Incorporating priorities for waiting customers in the hypercube queuing model with application to an emergency medical service system in Brazil. Eur J Oper Res. 2015; 242(1):274-285.

29. Iannoni AP, Morabito R, Saydam C. A hypercube queueing model embedded into a genetic algorithm for ambulance deployment on highways. Ann Oper Res. 2008; 157(1):207-224.

30. Mobin M, Li Z, Amiri M. Performance evaluation of Tehran-qom highway emergency medical service system using hypercube queuing model. Proceedings of the IIE Annual Conference and Expo 2015; 2015 May 2; Massachusetts, USA. Bepress; 2015.

31. Takeda RA, Widmer JA, Morabito R. Analysis of ambulance decentralization in an urban emergency medical service using the hypercube queueing model. Comput Oper Res. 2007; 34(3):727-741.

32. Aliaga M, Gunderson B. Interactive statistics. 3rd ed. Upper Saddle River, N.J.: Pearson Prentice Hall; 2006.

33. Cabral EL dos S, Castro WRS, Florentino DR de M, et al. Response time in the emergency services: Systematic review. Acta Cir Bras. 2018;33(12):1110-1121. 
Figures

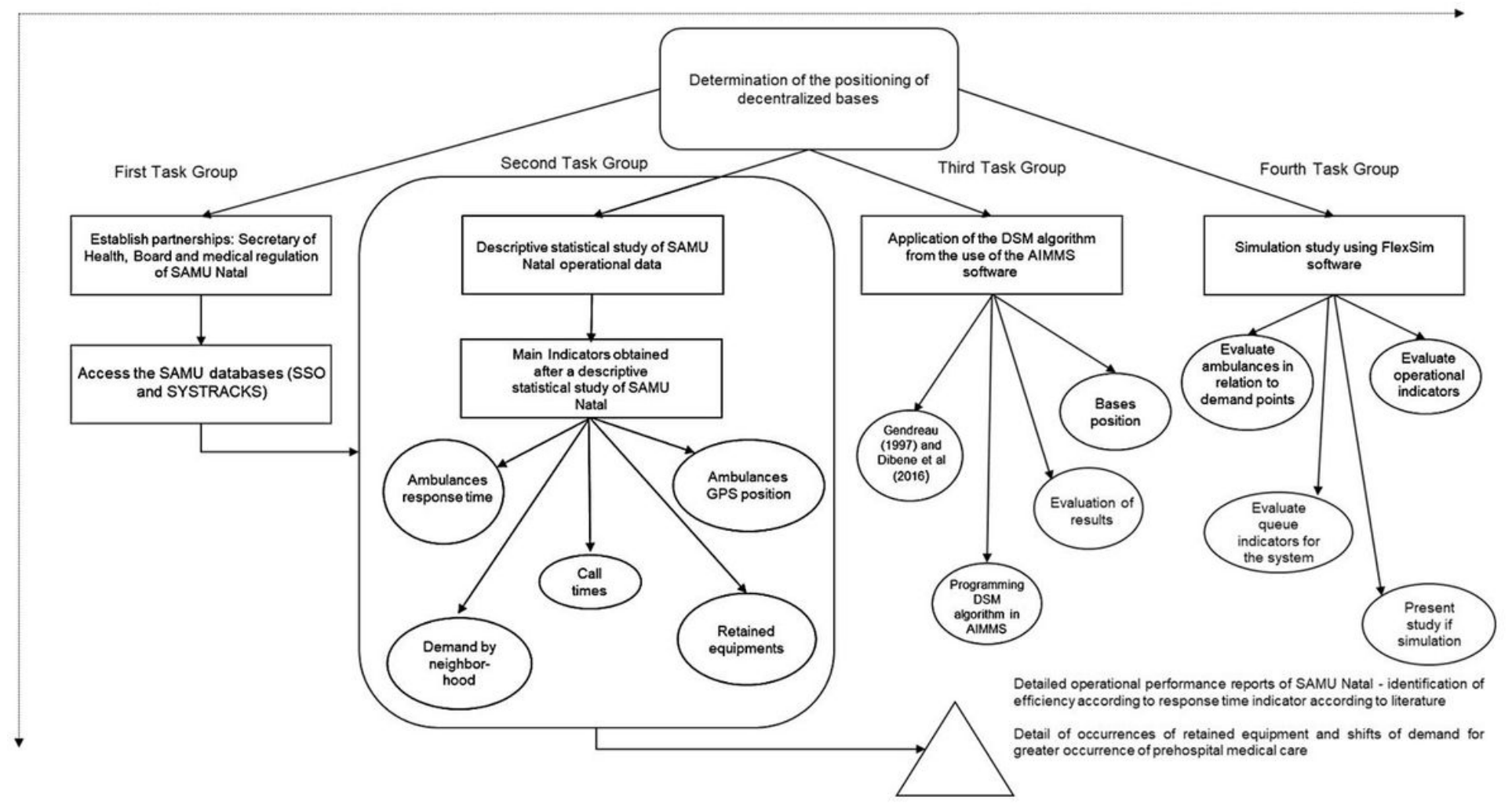

Figure 1

Steps to work.

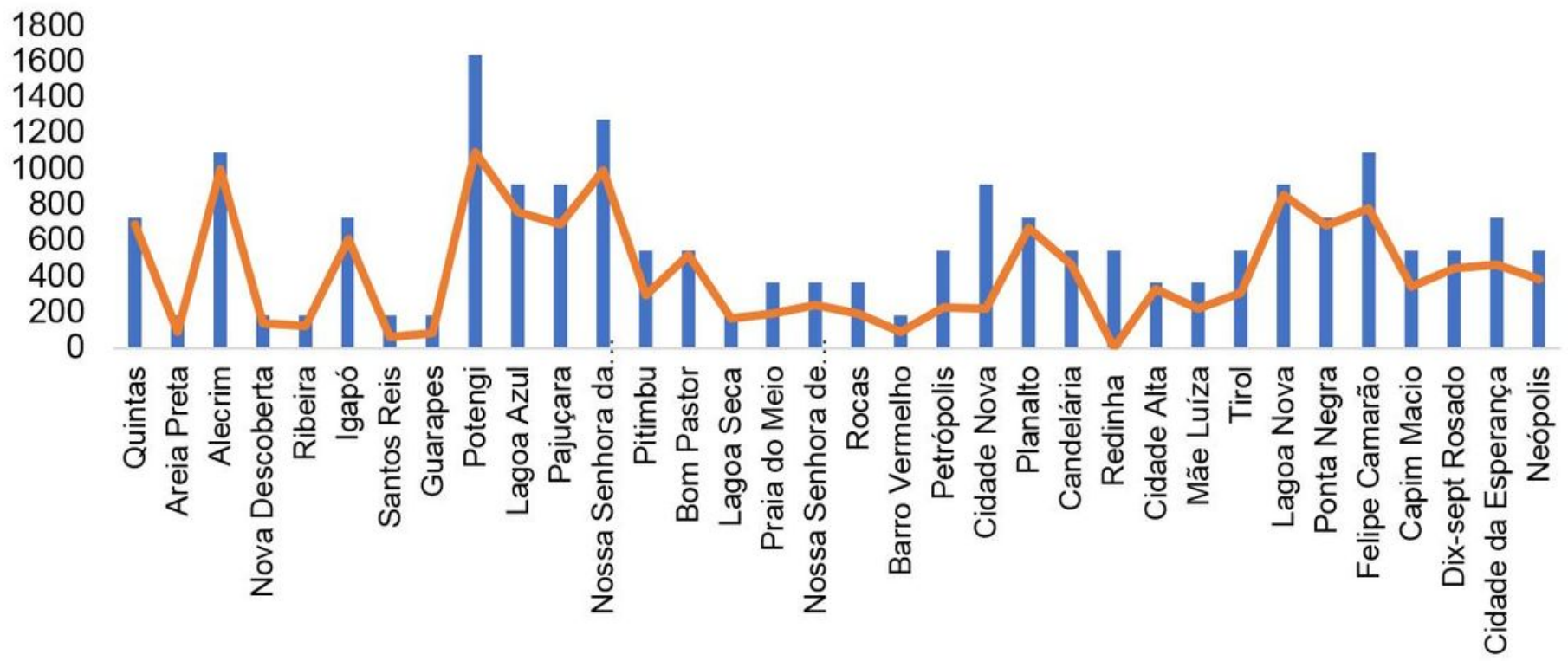

Figure 2 
Comparison between real and simulated calls.

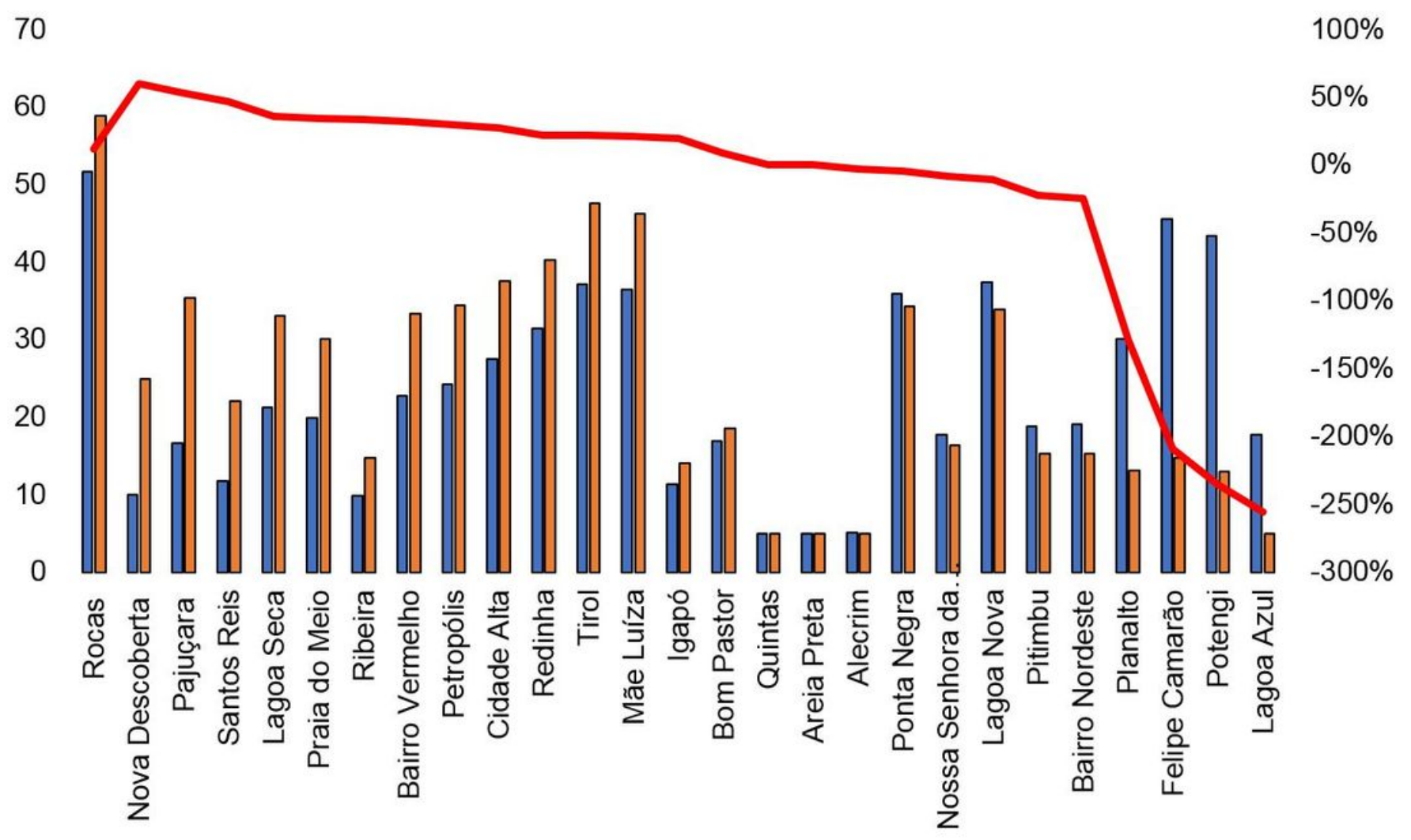

Figure 3

Simulated time with current bases position and bases proposed by the DSM algorithm. 